$1-2000$

\title{
Effects of Foot Orthoses on Skeletal Motion During Running
}

\author{
A. Stacoff \\ University of Calgary \\ C. Reinschmidt \\ University of Calgary \\ B. M. Nigg \\ University of Calgary
}

Antonie J. van den Bogert

Cleveland State University, a.vandenbogert@csuohio.edu

A 'Iniversity Hospital, Huddinge, Sweden

Part of the Biomechanical Engineering Commons

How does access to this work benefit you? Let us know!

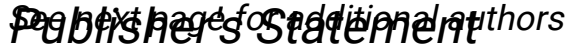

NOTICE: this is the author's version of a work that was accepted for publication in Clinical Biomechanics. Changes resulting from the publishing process, such as peer review, editing, corrections, structural formatting, and other quality control mechanisms may not be reflected in this document. Changes may have been made to this work since it was submitted for publication. A definitive version was subsequently published in Clinical Biomechanics, 15, 1, (01-01-2000); 10.1016/S0268-0033(99)00028-5

\section{Original Citation}

Stacoff, A., Reinschmidt, C., Nigg, B. M., 2000, "Effects of Foot Orthoses on Skeletal Motion during Running," Clinical Biomechanics, 15(1) pp. 54-64.

This Article is brought to you for free and open access by the Mechanical Engineering Department at EngagedScholarship@CSU. It has been accepted for inclusion in Mechanical Engineering Faculty Publications by an authorized administrator of EngagedScholarship@CSU. For more information, please contact library.es@csuohio.edu. 


\section{Authors}

A. Stacoff, C. Reinschmidt, B. M. Nigg, Antonie J. van den Bogert, A. Lundberg, J. Denoth, and E. Stüssi 


\title{
Effects of foot orthoses on skeletal motion during running
}

\author{
A. Stacoff ${ }^{\mathrm{a}, \mathrm{e}, *}$, C. Reinschmidt ${ }^{\mathrm{a}, \mathrm{c}}$, B.M. Nigg ${ }^{\mathrm{a}}$, A.J. van den Bogert ${ }^{\mathrm{a}, \mathrm{d}}$, A. Lundberg ${ }^{\mathrm{b}}$, \\ J. Denoth ${ }^{\mathrm{e}}$, E. Stüssi ${ }^{\mathrm{e}}$ \\ " Human Performance Laboratory, The University of Calgary, Canada \\ b Karolinska Institute, Department of Orthopaedics, University Hospital, Huddinge, Sweden \\ ' Sulzer Orthopedics Ltd., Winterthur, Switzerland \\ d Biomedical Engineering, Lerner Research Institute, Cleveland Clinic Foundation, Cleveland, USA \\ ' Biomechanics Laboratory, Department of Materials, ETH Zürich, Waqistrasse 4, 8952 Schlieren, Switzerland
}

\section{Introduction}

Excessive eversion and excessive tibial rotation have been associated with various running injuries $[1,2]$ Excessive eversion has been linked to Achilles tendon problems $[3,4]$ and to shin splints $[5,6]$ whereas excessive tibial rotation has been associated with the development of knee injuries [2,7].

To reduce and control excessive movements, foot orthoses or shoe inserts are often applied medially inside

\footnotetext{
- Corresponding author.

E-mail address: stacoff@biomech.mat.ethz.ch (A. Stacoff)
}

the shoes. Studies analyzing the effect of such orthoses administered to injured runners generally report $70-80 \%$ positive outcomes $[1,7,8]$. This is a rather surprising result since the orthoses tested in these studies differed considerably in shape, material properties (ranging from flexible to rigid) and placements. The lack of a consensus on the appropriate application of shape, material properties and placement of foot orthoses indicates that the knowledge on which these decisions were based is small and incomplete.

Effects produced by orthoses may be the result of mechanical and/or proprioceptive mechanisms. Orthoses are thought to reduce foot eversion and/or increase 
the afferent feedback from cutaneous receptors in the foot [9], which is assumed to change the innervation pattern and, consequently, the movement. However, the quantification of these cause and effect processes is not trivial and the determination of the actual skeletal foot movement is difficult, since skeletal kinematics are masked by soft tissue movements [10,11].

Several groups have studied the effect of foot orthoses on rearfoot movement using various orthotic designs, materials, and placements as well as varus wedged shoes, but the results were inconsistent. One group of authors found significant differences in rearfoot movements as a result of these interventions [12-16] whilst another did not [17-21]. Nigg et al. [20] reported a reduction of initial pronation (eversion) as a result of medial orthoses but not of total pronation, and found that a posterior support inside the shoe (support beneath the sustentaculum tali) was more effective in reducing initial eversion than more anterior placements. However, the reasons for these results are not well understood.

Foot movement is transferred to the tibia by a coupling mechanism [22-25]. Consequently, it has been proposed that excessive eversion may be transferred into excessive tibial rotation $[4,5,7]$. Thus, it may be concluded that orthoses may have an effect on this movement coupling and may consequently affect tibial rotation. However, effects of orthoses on the transfer of the foot movement to the tibia during running have not yet been studied, and hence, orthotic effects on the kinematics of the lower extremities are currently not well understood.

Studies related to the kinematics of running and orthotic effects are based on skin or shoe mounted marker settings. Recent studies comparing skin/shoe markers with bone pin markers indicate that externally mounted markers overestimate the movements of the underlying bone [10,11]. Therefore, external markers cannot be used to obtain precise skeletal kinematics information. Hence, the purpose of this study was to quantify the effect of medially placed orthoses on calcaneal eversion and tibial rotation using markers mounted on bone pins.

The hypotheses to be tested in this study were:

I. Posterior orthoses are more effective in decreasing maximum eversion and internal tibial rotations compared with anterior orthoses.

II. Medially placed orthoses (anterior and posterior) decrease maximum eversion and internal tibial rotation compared with no orthoses.

\section{Methods}

\subsection{General project description}

The experiments were performed at the Department of Orthopaedic, Karolinska Institute at Huddinge University Hospital, Stockholm. The project was part of a larger study performed at the University of Calgary, Canada $[11,26,27]$. Ethical approval for the experiments was obtained from the Ethics committee of the Karolinska Hospital and by the Medical Ethics Committee of The University of Calgary.

Briefly, five healthy male volunteers participated in this study (mean 28.6 (SD 4.3 years), mean mass 83.4 (SD 10.2) kg, mean height $185.1(\mathrm{SD} 4.5) \mathrm{cm}$ ); they were all injury free, were no overpronators, and had no previous injury history which may have influenced their locomotion patterns. The subjects gave their informed consent to participate in the study, and the entire procedure was explained to them before testing. The subjects familiarized themselves with the running procedure before surgery and again before being filmed with inserted bone pins. Intracortical Hofmann pins with reflective marker triads were inserted under standard local anesthetic (Citanest $10 \mathrm{mg} / \mathrm{ml}$ ) which was active for 2-3 $\mathrm{h}$, leaving enough time for the experiments. Two bone pins were drilled into the posterior lateral aspect of calcaneus and the anterior lateral aspect of the tibial condyle. Immediately after surgery, reflective marker triads were screwed onto each bone pin (Fig. 1). Subject follow-ups, several months after testing, showed no complications. Three markers were glued onto the test shoes, one at the posterior lateral aspect of the calcaneus, and two in the midfoot, to avoid marker merging (marker 2 at the location of the medial cuneiform, marker 3 at the lateral tuberosity of the fifth metatarsal, Fig. 1).

\subsection{Experimental set-up and testing procedure}

Three high-speed cine cameras (LOCAM, $16 \mathrm{~mm}$, Red Lake Lab., Santa Clara, USA) were focused in umbrella form on a force platform (KISTLER, Winterthur, Switzerland) which was mounted flush to the runway [11,26]. The camera speed was set at $200 \mathrm{~Hz}$ and three LEDs, triggered by a threshold detector connected

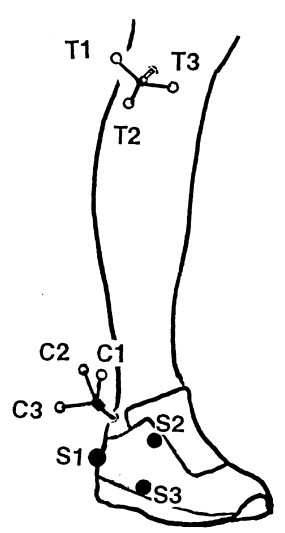

Fig.1. Bone pin marker positioning: at the tibia from $\mathrm{T} 1$ to $\mathrm{T} 3$, at the calcaneus from $\mathrm{C} 1$ to $\mathrm{C} 3$, at the shoe from $\mathrm{S} 1$ to $\mathrm{S} 3$. 
to the force plate, were used to synchronize the cameras. Fluctuations in camera speed were corrected using the signals of internal camera timing LED signals. A calibration frame with six control points $\left(0.5 \times 0.5 \times 0.5 \mathrm{~m}^{3}\right)$ was used for the three-dimensional reconstruction.

The accuracy of the spatial reconstruction between two marker triads was determined twice: (i) based on the residuals of the DLT equations averaged over the entire stance phase and was found to be in the order of $\pm 4^{\circ}$ (including noise error and lens distortion error), and (ii) based on the deviations of the inter-marker distances of the same trials where the mean error (RMS) was found to be $\pm 1.0^{\circ}$ (including noise error only). Thus, for the present study, a realistic estimation of the error was likely between the two errors given above. The error of the shoe data was about $\pm 1.0^{\circ}$ higher than that at the bone, because it included inaccuracies of different standing trials with different shoes.

The subjects performed heel-toe running trials with a running speed of between 2.5 and $3.0 \mathrm{~m} / \mathrm{s}$ measured with two photo cells placed $0.7 \mathrm{~m}$ in front and behind the force platform with a few steps for adaptation to the new shoe condition between each trial. Each of the test conditions was repeated three times with the exception of that with no orthoses, which was repeated five times. Trials were repeated if the subjects did not land with their right foot on the force plate or if they obviously modified their step length in order to hit the force plate.

\subsection{Orthoses used in the study}

The tests were performed with three orthotic conditions. The test shoes (Adidas Equipment Cushioning, 1994) had a $2.8 \mathrm{~cm}$ dual density midsole with a midsole hardness of Shore A 35 laterally (softer) and Shore A 45 medially (harder). The heel counter of the right shoe had a specially constructed cutout to prevent impingement with the calcaneal pin (Fig. 2). In the first condition, the standard manufactured insole was used, which was as- sumed to have minimal mechanical support. In the second and third conditions, special orthoses were mounted onto the manufacturers insole (Fig. 2). The orthoses were made from cork with a $1 \mathrm{~cm}$ maximum thickness and were thought to support the foot at two different locations: The anterior orthosis supported the foot arch, the posterior orthosis supported the calcaneus at the sustentaculum tali, vertically beneath the medial malleolus.

\subsection{Data analysis and reduction}

The procedure used to analyze the film followed the specifications developed and described by Reinschmidt $[11,26]$. Camera coordinates were filtered with a bi-directional 4th order low-pass Butterworth filter with a 10 $\mathrm{Hz}$ cut-off frequency. KineMat, a set of programs written in MATLAB ${ }^{\text {TM}}$, was adapted from Reinschmidt and van den Bogert [27] for the specific needs of this investigation to reconstruct the three-dimensional position of the markers and to calculate the relative segmental movements. The 3D reconstruction, based on a standard direct linear transformation method, was performed for the running trials and one standing barefoot trial of each subject. The barefoot standing trial was used as the neutral position, to define the segment-fixed coordinate systems of the calcaneus and tibia, for which the subjects were instructed to stand with straight knees, the ankle in the neutral position of $90^{\circ}$ dorsiflexion and the feet aligned parallel to the force platform representing the laboratory coordinate system. This implied that during barefoot standing all joint rotations equaled zero. The standing trials with the respective shoe condition was used for the shoe marker analysis.

The rotations were calculated as Cardanic angles for the stance phase of all test conditions using a joint coordinate system approach (JCS) at the ankle joint complex with the defined sequence of rotations of plantar/dorsiflexion about a tibia fixed medio-lateral

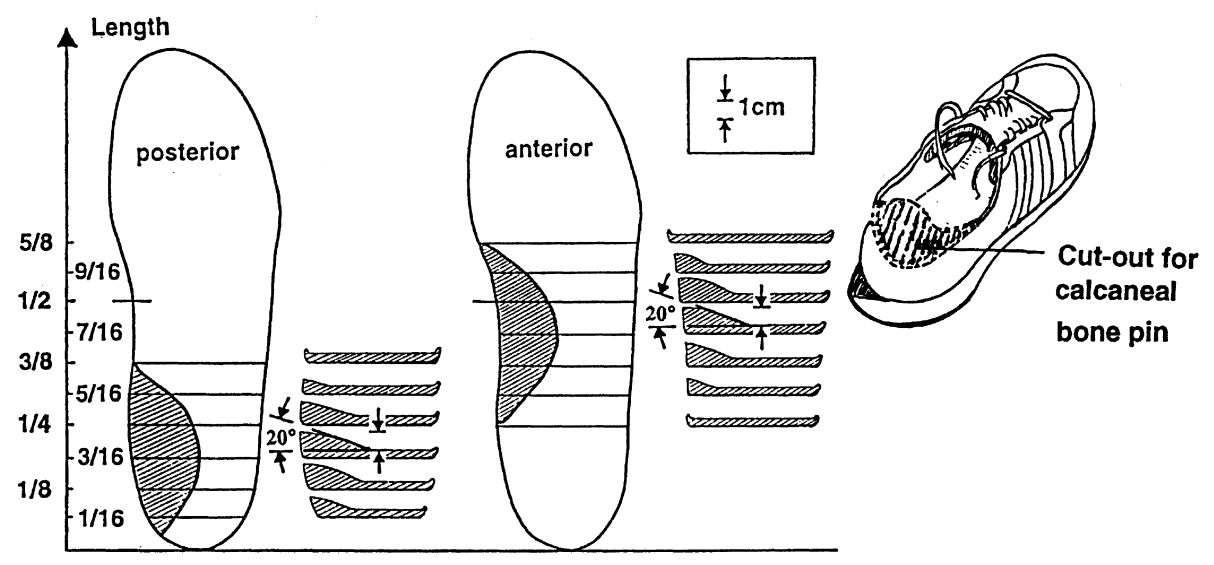

Fig. 2. Test shoes and orthoses used in the study. 
axis, calcaneal ab/adduction about the floating axis, and in/eversion about the antero-posterior axis of the calcaneus [28]. Tibial rotation ("corresponding" to $\mathrm{ab} /$ adduction in the above sequence) was calculated using the sequence: tibial rotation about a tibia fixed proximal-distal (longitudinal) axis, in/eversion about the floating axis, and plantar/ dorsiflexion about a calcaneus fixed medio-lateral axis [29].

\subsection{Definition of variables}

In/eversion and tibial rotation variable definitions are explained in Table 1 and in previous publications $[11,26]$. The variables were defined between touchdown and midstance of running. The inversion positions at touchdown $\left(\beta_{0}\right.$ and $\left.\rho_{0}\right)$ were considered to detect possible adaptations to shoe interventions before touchdown. Excessive eversion (i.e. $\beta_{\max }$ and $\Delta \beta_{\max }$ ) has been suggested to force the Achilles tendon to bend laterally, hereby producing an asymmetric stress distribution across the tendon which could lead to Achilles tendon problems $[3,4]$. Excessive eversion velocity $\left(\dot{\beta}_{\max }\right)$ has been associated with medial tibial stress syndrome $[5,6]$. Excessive tibial rotation $\left(\Delta \rho_{\max }\right)$ has been associated with changes in the tracking of the patella which may be related to the occurrence of the patellafemoral pain syndrome [30]. Tibial rotation is thought to take place as a result of the movement coupling from the calcaneus to the tibia. In addition to these variables, eversion of the shoe relative to the tibia was also determined, with the standing trial of each shoe condition being used for the definition of the neutral position for this purpose. However, it has to be kept in mind that two of the shoe markers were placed at the midfoot. Thus, strictly spoken, shoe eversion of the present study was a combination of shoe eversion at the calcaneus and at the midfoot.
The testing procedure was organized such that test conditions were independent from each other. As mentioned above, the present study was part of a larger study with a total of 115 test trials. All variables of the present study were found to be normally distributed (when testing over all 115 trials) performing the Kolmogorov-Smirnov test. The variables were tested with two-tailed anova techniques with repeated measures, the one-way anova to test subject independent orthotic effects, the two-way anova to test subject dependent effects, as well as possible interactions between subjects and orthoses. In cases of contradicting results between the one-way and two-way anova, the more conservative result of the one-way anova was accepted. The power analysis conducted on the kinematic variables suggested that there was a $80 \%$ chance of detecting any differences in these variables between the test conditions which were greater than $3.5^{\circ}$.

\section{Results}

Eversion and tibial rotation movement patterns are presented in Fig. 3 (single curves of a typical subject) and Fig. 4 (mean curves of each condition for each subject). Eversion and internal tibial rotation took place from touchdown until midstance, thereafter, the movements reversed to inversion and external tibial rotation until take-off. These general movement patterns were found to be consistent for all subjects and test conditions.

At touchdown the calcaneus was inverted and the tibia was externally rotated by a few degrees. Maximum eversion averaged between $3.1^{\circ}$ and $4.1^{\circ}$ (mean $\beta_{\max }$ ) and total eversion averaged between $7.9^{\circ}$ and $8.2^{\circ}$ (mean $\left.\Delta \beta_{\max }\right)$ according to Table 2 . Total internal tibial rotation averaged between $3.2^{\circ}$ and $4.8^{\circ}$ (mean $\Delta \rho_{\max }$ ). The maximum eversion velocity averaged between $130 \%$

Table 1

Definition and functional explanation of variables used in this study ${ }^{\mathrm{a}}$

\begin{tabular}{|c|c|c|c|}
\hline Variable & Symbol & Definition & Justification \\
\hline Touchdown in/eversion & $\beta_{0}$ & $\begin{array}{l}\text { In/eversion position of calcaneus } \\
\text { (relative to tibia) at touchdown }\end{array}$ & $\begin{array}{l}\text { Orthoses may affect calcaneal } \\
\text { position before touchdown } \\
\text { changing initial conditions }\end{array}$ \\
\hline Maximum eversion & $\beta_{\max }$ & $\begin{array}{l}\text { Maximum eversion position of } \\
\text { calcaneus (relative to tibia) during } \\
\text { ground contact }\end{array}$ & $\begin{array}{l}\text { Excessive eversion has been } \\
\text { associated with Achilles tendon } \\
\text { problems }\end{array}$ \\
\hline Total eversion & $\Delta \beta_{\max }$ & $=\beta_{\max }-\beta_{0}$ & \\
\hline Maximum eversion velocity & $\dot{\beta}_{\max }$ & $\begin{array}{l}\text { Maximum eversion velocity of } \\
\text { calcaneus between } 10 \% \text { and } 40 \% \text { of } \\
\text { ground contact }\end{array}$ & $\begin{array}{l}\text { Excessive eversion velocity has been } \\
\text { associated with medial tibial stress } \\
\text { syndrome }\end{array}$ \\
\hline Total internal tibial rotation & $\Delta \rho_{\max }$ & $=\rho_{\max }-\rho_{0}$ & $\begin{array}{l}\text { Excessive tibial rotation has been } \\
\text { associated with patella-femoral pain } \\
\text { syndrome }\end{array}$ \\
\hline
\end{tabular}

\footnotetext{
${ }^{\mathrm{a}}$ The shoe variables were defined accordingly.
} 

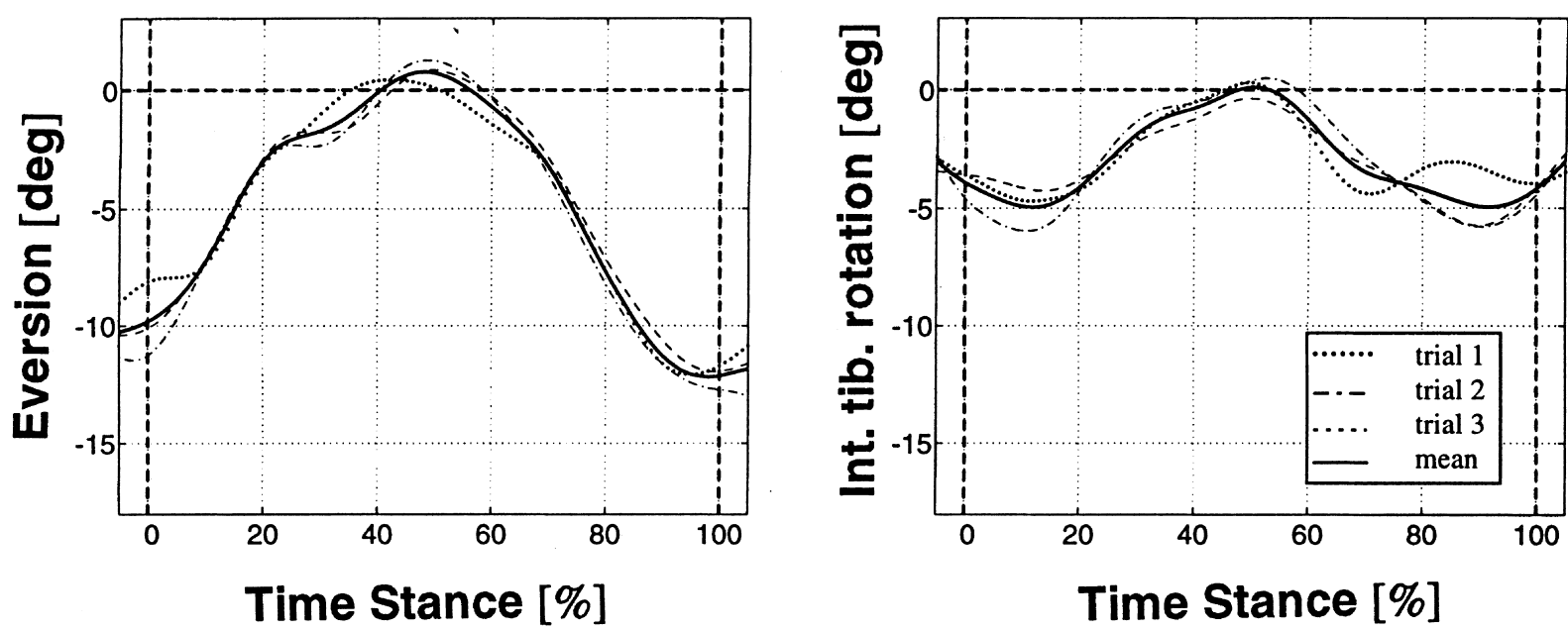

Fig. 3. Example of in/eversion and tibial rotation (subject 1 with anterior orthoses). Thin lines: three repetitions, thick lines: mean curve. Labels on the vertical axes indicate movements in the positive direction.
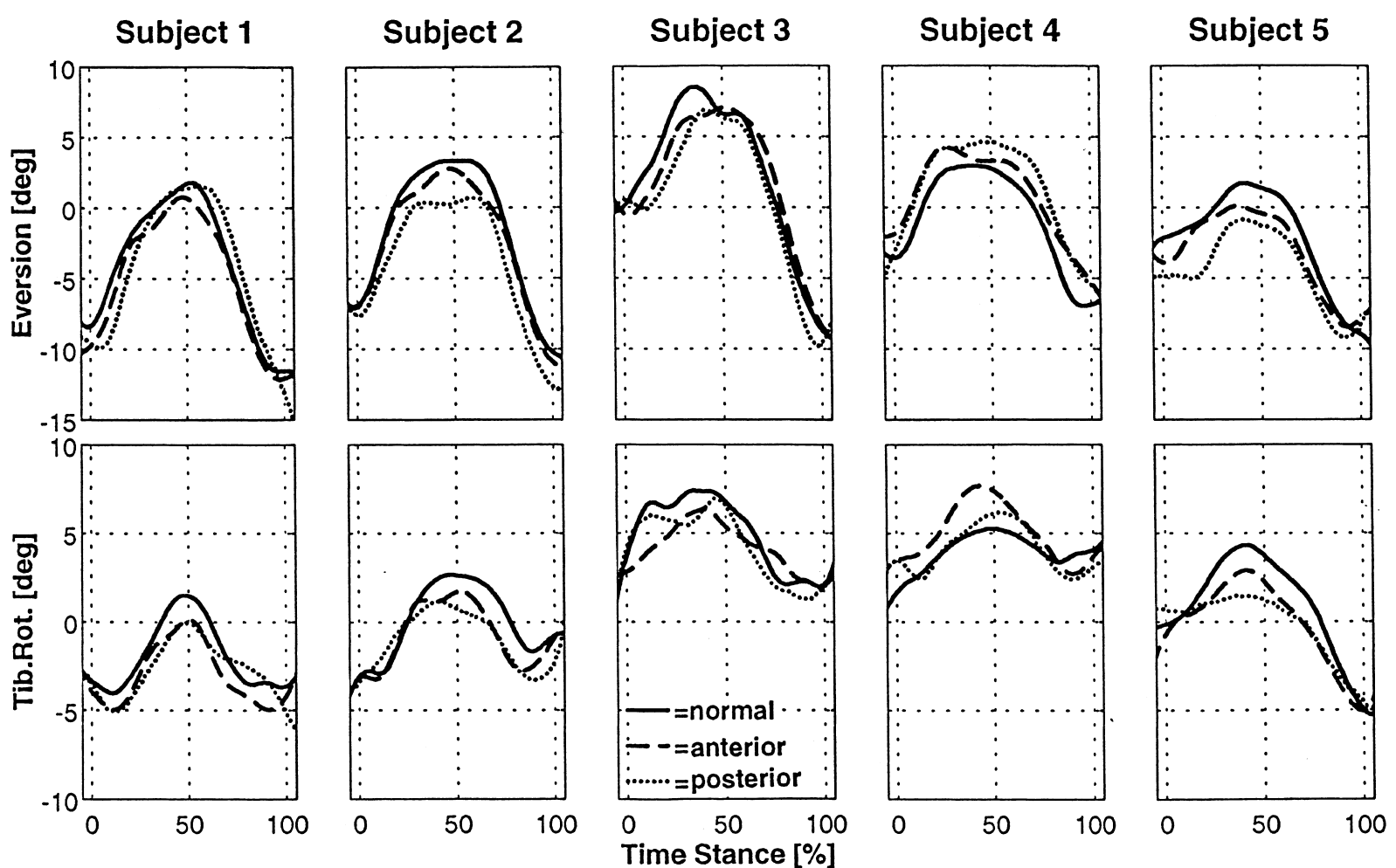

Fig. 4. Mean curves of in/eversion and tibial rotation of all conditions and all subjects: $(-)$ normal, $(--)$ anterior orthoses, $(\cdots)$ posterior orthoses. The standard deviation during the stance phase was on average $1.2^{\circ}$ for eversion and $1.5^{\circ}$ for tibial rotation.

and $137^{\circ}$ s and the difference between total skeletal and total shoe eversion averaged between $5.8^{\circ}$ and $7.3^{\circ}$ (Fig. 5), hence a relative movement between the shoe and the calcaneus was present for all subjects under all shoe conditions.

These results showed that during the stance phase of running at $2.5-3 \mathrm{~m} / \mathrm{s}$ foot orthoses had no substantial effects on skeletal calcaneal and tibial kinematics. Mean differences between the test conditions were less than $1.6^{\circ}$ and $10 \%$, which was smaller than the differences between subjects (up to $10^{\circ}$ and $80^{\circ} / \mathrm{s}$; Table 2). Additional statistical comparisons between subject and orthotic conditions were found to be significant $(p<0.01)$. The only variable that showed a significant difference independent of the subjects was the total internal tibial rotation $\left(\Delta \rho_{\max }\right)$ which was reduced as a result of medial orthoses $(p<0.05)$. Although subject 5 showed a very low value (Table $2: 1.27^{\circ}$ ) influencing the test results, all 
Table 2

Mean values (standard deviation) of the study variables ${ }^{\mathrm{a}}$

\begin{tabular}{|c|c|c|c|c|c|c|c|c|}
\hline Variable & Condition & Subject 1 & Subject 2 & Subject 3 & Subject 4 & Subject 5 & Mean & $\mathrm{SD}$ \\
\hline \multirow{3}{*}{$\beta_{0}\left(^{\circ}\right)$} & Normal & $-8.37(1.89)$ & $-6.80(1.20)$ & $0.10(0.61)$ & $-3.53(2.24)$ & $-2.16(1.47)$ & -4.15 & (3.44) \\
\hline & Posterior & $-9.64(0.97)$ & $-7.66(0.64)$ & $0.58(0.32)$ & $-2.98(1.13)$ & $-4.93(0.51)$ & -4.92 & (3.99) \\
\hline & Anterior & $-9.83(1.60)$ & $-7.02(0.61)$ & $-0.53(1.49)$ & $-1.91(0.52)$ & $-3.90(1.14)$ & -4.64 & (3.79) \\
\hline \multirow{3}{*}{$\beta_{\max }\left(^{\circ}\right)$} & Normal & $1.92(0.93)$ & $4.05(1.00)$ & $8.80(1.48)$ & $3.53(1.56)$ & $2.09(1.80)$ & 4.08 & $(2.79)$ \\
\hline & Posterior & $1.82(0.67)$ & $1.54(0.74)$ & $7.21(0.30)$ & $5.52(1.02)$ & $-0.85(1.25)$ & 3.05 & $(3.26)$ \\
\hline & Anterior & $0.85(0.40)$ & $3.06(0.71)$ & $7.50(1.05)$ & $4.41(2.41)$ & $0.42(2.28)$ & 3.25 & (2.88) \\
\hline \multirow{3}{*}{$\Delta \beta_{\max }\left(^{\circ}\right)$} & Normal & $10.29(1.89)$ & $10.85(1.94)$ & $8.70(1.44)$ & $7.05(3.49)$ & $4.26(2.46)$ & 8.23 & (2.67) \\
\hline & Posterior & $11.45(0.30)$ & $9.19(1.20)$ & $6.63(0.29)$ & $8.50(2.13)$ & $4.08(1.73)$ & 7.97 & $(2.78)$ \\
\hline & Anterior & $10.68(2.00)$ & $10.08(1.29)$ & $8.03(1.32)$ & $6.32(1.98)$ & $4.32(3.19)$ & 7.89 & (2.64) \\
\hline \multirow[t]{3}{*}{$\dot{\beta}_{\max }(\%)$} & Normal & 151.68 (49.69) & $157.41(51.66)$ & $138.18(39.29)$ & $141.25(82.46)$ & 73.17 (20.59) & 132.34 & (33.98) \\
\hline & Posterior & $171.44(24.45)$ & $122.13(34.76)$ & $110.78(21.42)$ & $148.40(18.93)$ & $96.87(10.36)$ & 129.92 & (29.94) \\
\hline & Anterior & $168.15(16.26)$ & $152.31(23.82)$ & $133.97(53.00)$ & $146.83(29.74)$ & 85.44 (29.94) & 137.34 & $(31.50)$ \\
\hline \multirow[t]{3}{*}{$\Delta \rho_{\max }\left(^{\circ}\right)$} & Normal & $4.91(1.85)$ & $6.09(1.07)$ & $4.24(1.82)$ & $3.86(0.50)$ & $4.97(1.29)$ & 4.81 & $(0.85)$ \\
\hline & Posterior & $3.64(0.77)$ & $4.93(0.74)$ & $3.06(2.51)$ & $3.21(2.35)$ & $1.27(0.22)$ & 3.22 & (1.32) \\
\hline & Anterior & $4.08(0.92)$ & $4.93(0.46)$ & $3.91(3.43)$ & $4.43(2.22)$ & $3.99(2.19)$ & 4.27 & $(0.42)$ \\
\hline
\end{tabular}

${ }^{a}$ Positive values represent eversion, and internal tibial rotation; negative values denote inversion.

other subjects showed consistently the lowest tibial rotation results with the posterior orthoses. Thus, hypothesis II was supported for total internal tibial rotation, but not for the eversion variables. Furthermore, since no significant differences were found between the two orthotic conditions hypothesis I could not be supported and the data of the posterior and anterior orthoses were pooled in the statistical analysis.

\section{Discussion}

Due to the invasive character of the study the number of subjects was limited to five, which did not allow an extensive statistical analysis. However, the general rotation patterns during running were very consistent and generally found to be similar to previous investigations using external markers in running [29-31], bone markers in running as well as bone markers in walking [32,33]. Differences between those investigations and this study are discussed below, including the results of the test variables (Tables 2 and 3, Fig. 4).

\subsection{Inversion at touchdown $\left(\beta_{0}\right)$}

All subjects consistently lowered their feet toward the ground in an inverted position, except for subject 3 . The differences in orthotic conditions were small ranging from subject $2\left(\right.$ less than $1^{\circ}$ ) to subject 5 (less than $3^{\circ}$ ) whereas the differences between the subjects were up to $10^{\circ}(p<0.01)$. Hence, the degree of inversion appeared to be independent of the test condition, indicating that the orthoses did not significantly affect the tibiocalcaneal position prior to touchdown. Furthermore, there was no significant interaction between the orthotic conditions and the subjects. Generally, the range of touchdown inversion values was found to agree with previous investigations using shoe markers [14,20].

\subsection{Variables of total movement $\left(\Delta \beta_{\max }, \Delta \rho_{\max }\right)$}

The differences in total eversion $\left(\Delta \beta_{\max }\right)$ between the orthotic conditions for each subject were in the order 1$2^{\circ}$, but the differences between the subjects were of the order $6-7^{\circ}(p<0.01$; Table 3$)$. Whereas subjects 2 and 3 showed an expected decrease of eversion with anterior and/or posterior orthoses, subject 1 showed an increase and subjects 4 and 5 no consistent change, resulting in no significant differences between test conditions. These results suggest that there were no systematic differences resulting from the use of medial orthoses. Furthermore, no significant interactions between subjects and orthotic conditions were found. The results of this study are in agreement with previous investigations [17-21] where small and insignificant decreases of eversion with orthoses of $1-4^{\circ}$ were reported. However, other investigations [13, 14] showed significant changes as a result of medially placed orthoses of $2-4^{\circ}$ and of varus wedged shoe soles of $5-9^{\circ}[15,16,34]$. These conflicting results may be explained by differences in shape and material properties of the tested orthoses and varus wedged soles as well as methodological differences such as marker placements. All these previous studies were based on skin and shoe mounted marker settings (and electrogoniometers [16]) which have been shown to overestimate the bone movements [11]. Hence, previous studies reporting on orthotic effects on eversion have to be interpreted with caution. 

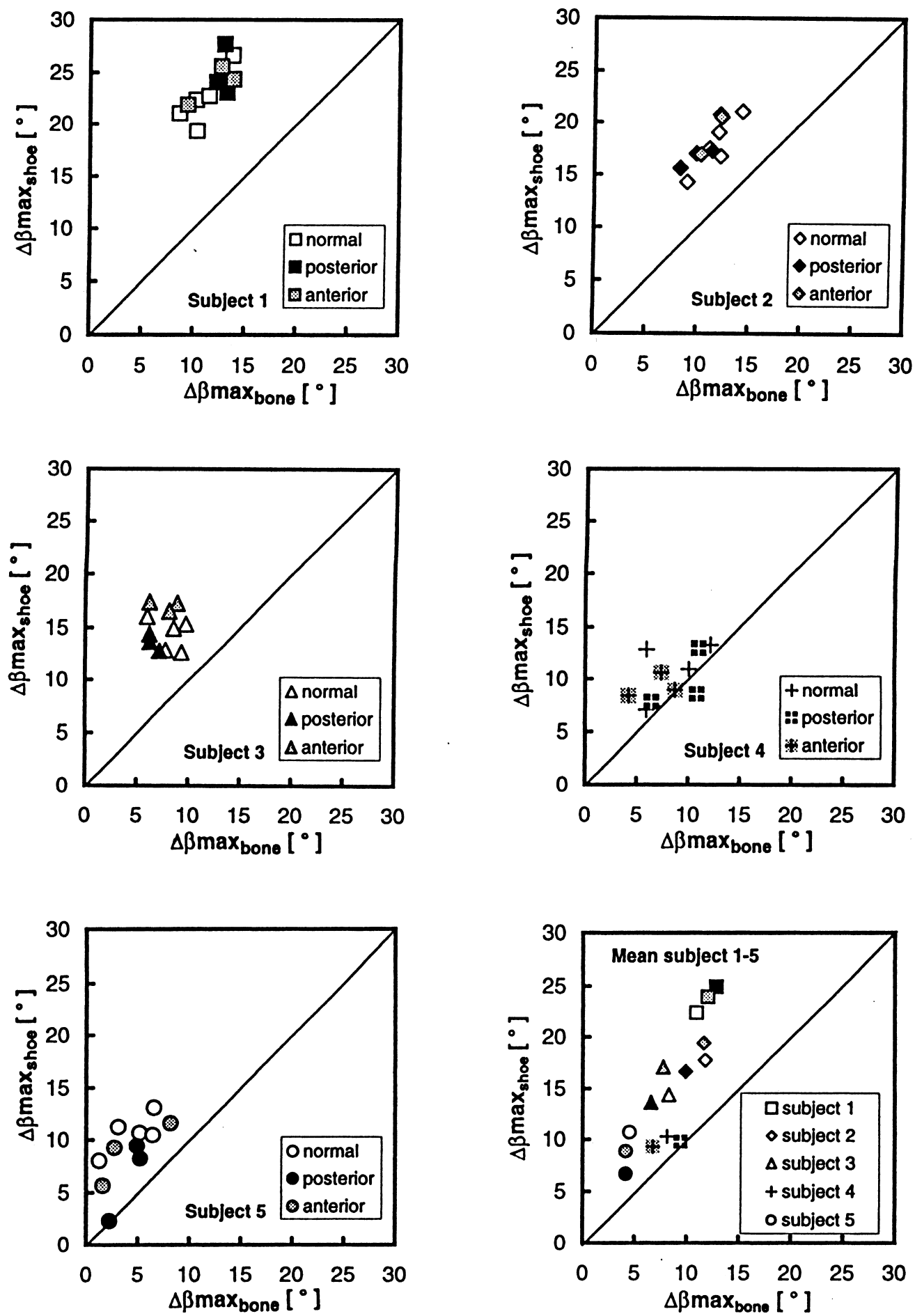

Fig. 5. Total eversion of the shoe relative to the bone. Diagrams "Subject 1-5": for each trial of all subjects. Diagram "Mean subject 1-5": Mean values of each shoe condition of all subjects. (Note: bone values may slightly differ from Table 2 because of different standing trial results from different shoes.)

The differences in total internal tibial rotation $\left(\Delta \rho_{\max }\right)$ between the orthotic conditions and between the subjects were small (exact values: $0.75^{\circ}$ and $3.7^{\circ}$ ) but significant $(p<0.05)$. All subjects showed a decrease in total internal tibial rotation with orthoses compared with the normal condition, with one exception (subject
4). Thus, it is concluded that medially placed orthoses may significantly decrease total internal tibial rotation which is in contrast to previous studies using electrogoniometers (Taunton et al. [13], no consistent orthotic effect; and Smart and Robertson [35], reduction of $2^{\circ}$, not significant) using external markers (Eng and $\mathrm{Pi}$ - 
Table 3

Study variable statistics ${ }^{\mathrm{a}}$

\begin{tabular}{|c|c|c|c|c|}
\hline \multirow[t]{2}{*}{ Variable } & \multicolumn{2}{|c|}{ Normal versus anterior-posterior } & \multicolumn{2}{|c|}{ Anterior versus posterior } \\
\hline & One-way anova & Two-way anova & One-way anova & Two-way anova \\
\hline \multicolumn{5}{|c|}{ Bone marker variables } \\
\hline \multirow[t]{3}{*}{$\beta_{0}$} & n.s. & 1 n.s. & n.s. & 1 n.s. \\
\hline & & $2<0.01$ & & $2<0.01$ \\
\hline & & 3 n.s. & & 3 n.s. \\
\hline \multirow{3}{*}{$\beta_{\max }$} & n.s. & $1<0.05$ & n.s. & 1 n.s. \\
\hline & & $2<0.01$ & & $2<0.01$ \\
\hline & & $3<0.05$ & & 3 n.s. \\
\hline \multirow[t]{3}{*}{$\Delta \beta_{\max }$} & n.s. & 1 n.s. & n.s. & 1 n.s. \\
\hline & & $2<0.01$ & & $2<0.01$ \\
\hline & & 3 n.s. & & 3 n.s. \\
\hline \multirow[t]{3}{*}{$\dot{\beta}_{\max }$} & n.s. & 1 n.s. & n.s. & 1 n.s. \\
\hline & & $2<0.01$ & & $2<0.01$ \\
\hline & & 3 n.s. & & 3 n.s. \\
\hline \multirow{3}{*}{$\Delta \rho_{\max }$} & $<0.05$ & $1<0.05$ & n.s. & 1 n.s. \\
\hline & & 2 n.s. & & 2 n.s. \\
\hline & & 3 n.s. & & 3 n.s. \\
\hline \multicolumn{5}{|c|}{ Shoe marker variables } \\
\hline \multirow[t]{3}{*}{$\beta_{\mathrm{o} / \text { shoe }}$} & n.s. & $1<0.01$ & n.s. & $1<0.01$ \\
\hline & & $2<0.01$ & & $2<0.01$ \\
\hline & & $3<0.01$ & & $3<0.05$ \\
\hline \multirow{3}{*}{$\beta_{\max / \text { shoe }}$} & n.s. & 1 n.s. & n.s. & 1 n.s. \\
\hline & & $2<0.01$ & & $2<0.01$ \\
\hline & & $3<0.01$ & & $3<0.05$ \\
\hline \multirow{3}{*}{$\Delta \beta_{\max / \text { shoe }}$} & n.s. & 1 n.s. & n.s. & 1 n.s. \\
\hline & & $2<0.01$ & & $2<0.01$ \\
\hline & & 3 n.s. & & 3 n.s. \\
\hline \multirow{3}{*}{$\dot{\beta}_{\max / \text { shoe }}$} & n.s. & 1 n.s. & n.s. & $1<0.05$ \\
\hline & & $2<0.01$ & & $2<0.01$ \\
\hline & & 3 n.s. & & 3 n.s. \\
\hline
\end{tabular}

${ }^{\mathrm{a}}$ The following abbreviations are used: $1=$ difference between orthotic conditions; $2=$ difference between subjects; $3=$ interaction between orthoses and subjects.; n.s. $=$ not significant.

errynowski [19], no effect) and using bone pins in walking (Lafortune et al. [33], reduction of $1-3^{\circ}$, not significant).

Summarizing the results on total eversion and internal tibial rotation, it can be concluded that small decreasing effects were apparent. The reduction in eversion was not systematic over all subjects and not significant, in contrast to internal tibial rotation where the reduction was systematic (one exception: subject 4 anterior orthoses) and significant.

\subsection{Maximum eversion $\left(\beta_{\max }\right)$}

It was expected that orthoses would reduce maximum eversion which was the case in subjects $1,2,3,5$, but not in subject 4 . The posterior orthoses were no more effective in decreasing maximum eversion than the anterior orthoses, thus hypothesis I was rejected. The differences between the normal shoe condition and both orthoses were not significant (one-way anova) showing significant interactions between orthoses and subjects $(p<0.05)$. Maximum eversion showed a reduction with orthoses of $1-3^{\circ}$ (exception subject 4 ) but hypothesis II could not be supported.

\subsection{Maximum eversion velocity $\left(\dot{\beta}_{\max }\right)$}

The differences of maximum eversion velocity between the subjects (in the order $50-100 \%$ s between subjects 1 and 5) was larger $(p<0.01)$ than the differences between the orthotic conditions (maximum of $25 \%$ for subject 2 ). It was expected that orthoses would decrease maximum eversion velocity, which was found in subjects 2 and 3 . The other three subjects, however, showed an increased velocity, thus suggesting that there was no systematic orthotic effects on the maximum eversion velocity. As expected $\dot{\beta}_{\max }$ measured at the bone level (between $73 \%$ s and $171 \%$ s, Table 2) was smaller compared with studies using shoe markers where eversion velocities have been reported between $408 \%$ s and $532 \%$ s $[14,15]$. Thus, considerable differences between skeletal velocities and velocities measured with shoe 
markers were observed which indicated a relative movement between bone markers and shoe markers.

\subsection{Shoe eversion versus bone eversion}

The comparison of total eversion measured at the shoe $\left(\Delta \beta_{\max / \text { shoe }}\right)$ with that at the bone (calcaneus, $\left.\Delta \beta_{\max / \text { bone }}\right)$ is shown in Fig. 5. It is evident that the differences between the subjects were larger than those between the shoe conditions. Therefore, not only bone movements were found to be typical for each subject but also shoe movements, even though all five subjects used the same running shoe model and the same orthoses.

Intraindividually, all five subjects (except subject 4) showed a significantly larger eversion of the shoe compared with the bone $(p<0.01)$, indicating that the shoes moved relative to the underlying calcaneus. The relative movement was smallest at touchdown (between $1^{\circ}$ and $3^{\circ}$ ) and largest at maximum eversion (as large as $11-12^{\circ}$ for subject 1 , but also as small as $0-3^{\circ}$ for subject 4 , Fig. $5)$. This change of the relative movement from touchdown to midstance was also reported by van Gheluwe [36], using skin markers viewed through windows cut into the shoes. Other reported values of relative movements between skin markers and shoe markers were found to be $2-4^{\circ}[14,20,36]$, thus smaller than in the present study.

Maximum eversion velocity measured at the shoe varied between $75 \%$ and $300 \%$ s showing smaller values compared with previous studies with shoe markers (between $408 \%$ s and $532 \%$ s) for running speeds between 3 and $4 \mathrm{~m} / \mathrm{s}[14,15]$. The lower angular velocities of this study may be explained by the slower running speeds $(2.5-3 \mathrm{~m} / \mathrm{s})$. The shoe variables showed no significant differences based on the one-way anova (Table 3). Significant interactions were found for the touchdown variable and the maximum shoe eversion.

\subsection{Limitations and considerations}

The results of this study show that there were no substantial or systematic orthotic effects over all subjects and test variables. Only hypothesis II could be partially supported for total internal tibial rotation. There are a number of reasons that may explain these results which are discussed below.

The orthoses applied in this study were not individually constructed. Hence, possible anatomical differences between the test subjects were not accounted for. Posteriorly placed orthoses are believed to support the calcaneus beneath the sustentaculum tali. However, whether this mechanical support works in all subjects and/or under different testing conditions (i.e. fatigued versus non-fatigued) is currently not known.

The cutout on the lateral heel counter of the tests shoes (Fig. 2) was necessary to prevent impingement with the calcaneal bone pin. However, this cutout may have reduced heel counter rigidity and the fit of the heel inside the shoe which may be needed for the orthoses to be effective. Furthermore, in most previous investigations shoe markers mounted at the heel counter have been used. Markers placed in other areas of the foot quantifying midfoot and/or forefoot movements have not been used systematically to date. Thus, it is possible that and midfoot and forefoot movements may be more important to the understanding of orthotic effects and that the calcaneus may not be the relevant bone to be assessed.

The invasive character of this study required the application of local anesthesia at the bone pin insertion site. Reinschmidt et al. [11], using the same subjects and shoes in their investigation, studied the effect of bone pin insertion (and local anesthesia) on skin-marker-based tibiocalcaneal rotations in a pilot study and concluded that the pre/post-operative knee and ankle joint rotations showed similar results, maximum differences being $2^{\circ}$. However, despite the results of this pilot study it remains unknown if subjects would adapt their individual running patterns when using orthoses if local anesthesia was not present.

Furthermore, the fact that successful injury treatment can be achieved with flexible, semirigid or rigid orthoses suggests that orthotic effects may be caused by proprioceptive reasons. It is possible that orthoses placed in the midfoot and forefoot may increase the afferent feedback from cutaneous receptors [9] which may lead to decreased eversion because of muscular contraction of inverting muscles. Indirect evidence from cadaver studies showed that when pulling forces are applied on $\mathrm{m}$. tibialis posterior, eversion is reduced and the movements at the midfoot joints are changed [37]. Further support is provided by Fromme et al. [38] who found that with increasing fatigue pronation increased; suggesting that muscular activity may play an important role in the control of eversion during the stance phase of running.

The results of this investigation showed that the study variable differences between the subjects were larger than the differences between the different test conditions. This suggests that each subject may have moved within his individual movement pattern despite the different orthotic conditions. Thus, for a given running task there may be various solutions with respect to the magnitude of rotations between segments of the lower extremity, an observation which is supported by the work of Engsberg and Andrews [39] and Lafortune et al. [33]. Thus, running may be associated with individual movement patterns such that a mechanical support (medially placed orthoses) cannot change them substantially. Alternatively, even a small decrease of any rotation (as observed in this study) may reduce the risk of injury considerably. However, it is presently not established how large such a relevant difference might be. 


\section{Conclusion}

In conclusion, this in vivo study showed that medially placed foot orthoses did not substantially change tibiocalcaneal movement patterns during running of normal subjects. Orthotic effects on eversion and tibial rotations were found to be small and unsystematic over all subjects. Differences between the subjects were significantly larger (up to $10^{\circ} ; p<0.01$ ) than between the orthotic conditions $\left(1-4^{\circ}\right)$. Significant orthotic effects across the subjects were found only for total internal tibial rotation $(p<0.05)$.

The results of this study suggest that effects of medially placed foot orthoses on tibiocalcaneal movement patterns during running may only be small. It is speculated that orthotic effects may be mechanical as well as proprioceptive, that mid-foot and fore-foot movements may be more important to the understanding of orthotic effects, and that the calcaneus may not be the relevant bone to be assessed.

\section{Acknowledgements}

This study was supported by the Swedish Defense Material Administration, the Swiss Federal Sports Commission (ESK), the Olympic Oval Endowment Fund of Calgary and ADIDAS America. The help of R. Lawson, H. Strebel and E. Avramakis at various stages of the project was greatly appreciated. The authors would like to thank S. Drevemo and C. Johnston of the Swedish University of Agricultural Science in Uppsala for providing movement analysis equipment.

\section{References}

[1] James SL, Bates BT, Osternig LR. Injuries to runners. American Journal of Sports Medicine 1978;6:40-50.

[2] van Mechelen W. Running injuries, a review of the epidemiological literature. Sports Medicine 1992;14:320-35.

[3] Smart GW, Taunton JE, Clement DB. Achilles tendon disorders in runners - a review. Medicine and Science in Sports and Exercise 1980;12(4):231-43.

[4] Clement DB, Taunton JE, Smart GW, McNicol KL. A survey of overuse running injuries. The Physician and Sports Medicine 1981;9:47-58.

[5] Segesser B, Nigg BM. Insertionstendinosen am Schienbein, Achillodynie und. Überlastungsfolgen am Fuss. - Ätiologie, Biomechanik, therapeutische Möglichkeiten. Orthopaede 1980;9:207-14.

[6] Viitasalo JT, Kvist M. Some biomechanical aspects of the foot and ankle athletes with and without shin splints. The American Journal of Sports Medicine 1983;11:125-30.

[7] James SL, Jones DC. Biomechanical aspects of distance running injuries. In: Cavanagh PR, editor. Biomechanics of distance running. Champaign (IL): Human Kinetics, 1990:249-69.

[8] Gross ML, Davlin LB, Evanski PM. Effectiveness of orthotic shoe inserts in the long-distance runner. The American Journal of Sports Medicine 1991;19(4):409-12.
[9] Feuerbach JW, Grabiner MD, Koh TJ, Weiker GG. Effect of an ankle orthosis and ankle ligament anaesthesia on ankle joint proprioception. American Journal of Sports Medicine 1994;22:223-9.

[10] Cappozzo A, Catani F, Leardini A, Benedetti MG, Della Croce $\mathrm{U}$. Position and orientation in space of bones during movement, experimental artefacts. Clinical Biomechanics 1996;11:90-100.

[11] Reinschmidt C, van den Bogert AJ, Murphy N, Lundberg A, Nigg BM. Tibiocalcaneal motion during running, measured with external and bone markers. Clinical Biomechanics 1997;12:8-16.

[12] Cavanagh PR, Clarke TE, Williams KR, Kalenak A. An evaluation of the effect of orthotics on pressure distribution and rearfoot movement during running. Proceedings of the American Orthopaedic Society for Sports Medicine. New York: Lake Placid, 1978.

[13] Taunton JE, Clement DB, Smart GW, Wiley JP, McNicol KL. A triplanar electrogoniometer investigation of running mechanics in runners with compensatory overpronation. Canadian Journal of Applied Sports Science 1985;10(3):104-15.

[14] Clarke TE, Frederick EC, Hamill CL. The study of rearfoot movement in running. In: Frederick EC, editor. Sport shoes and playing surfaces. Champaign (IL): Human Kinetics, 1984:166189.

[15] van Woensel W, Cavanagh PR. A perturbation study of lower extremity motion during running. Journal of Sports Biomechanics $1992 ; 8: 30-47$

[16] Milani TL, Schnabel G, Hennig EM. Rearfoot motion and pressure distribution patterns during running in shoes with varus and valgus wedges. Journal of Applied Biomechanics 1995;11:177-87.

[17] Bates BT, James SL, Osternig LR. Foot function during the support phase of running. American Journal of Sports Medicine 1979;7:328.

[18] Rodgers NM, LeVeau BF. Effectiveness of foot orthotic devices used to modify pronation in runners. The Journal of Orthopaedic and Sports Physical Therapy 1982;4:86-90.

[19] Eng JJ, Pierrynowski MR. The effect of soft foot orthotics on three-dimensional lower-limb kinematics during walking and running. Physical Therapy 1994;74:836-43.

[20] Nigg BM, Bahlsen A, Denoth J, Luthi S, Stacoff A. Factors influencing kinetic and kinematic variables in running. In: Nigg $\mathrm{BM}$, editor. Biomechanics of running shoes. Champaign (IL): Human Kinetics, 1986:139-60.

[21] Nigg BM, Kahn A, Fisher V, Stefanyshyn D. The effect of shoe insert construction on foot and leg movement during running. Medicine and Science in Sports and Exercise 1998;30(4):550-5.

[22] Olerud C, Rosendahl Y. Torsion-transmitting properties of the hind foot. Clinical Orthopaedics and Related Research 1985;214:285-94.

[23] Lundberg A. Kinematics of the ankle and foot, in vivo roentgen stereophoto-grammetry. Acta Orthop. Scand 1989;60 Suppl. 233:1-26.

[24] Hintermann B, Nigg BM, Sommer C. Foot movement and tendon excursion, An in vitro study. Foot and International 1994;15(7):386-95.

[25] Inman VT. The influence of the foot-ankle complex on the proximal skeletal structures. Artificial Limbs 1969;13(1):59-65.

[26] Reinschmidt C, van den Bogert AJ, Lundberg A, Murphy N, Nigg BM, Stacoff A, Stano A. Tibiofemoral and tibiocalcaneal motion during walking: external vs. skeletal markers. Gait and Posture 1997;6:98-109.

[27] Reinschmidt C, van den Bogert AJ. KineMat, a MATLAB ${ }^{\text {TM }}$ toolbox for the reconstruction of spatial marker positions and the analysis of three-dimensional joint movements. http,//www.Iri. ccf.org/isb/software/kinemat/, 1997c.

[28] Cole GK, Nigg BM, Ronsky JL, Yeadon MR. Application of the joint coordinate system to three-dimensional joint attitude and 
movement representation, a standardization proposal. Journal of Biomechanical Engineering 1993;115:344-9.

[29] Nigg BM, Cole GK, Nachbauer W. Effects of arch height of the foot on angular motion of the lower extremities in running. Journal of Biomechanics 1993;26:909-16.

[30] Stergiou P. Biomechanical factors associated with patellofemoral pain syndrome in runners. Unpublished Master Thesis. The University of Calgary, Alta., Canada, 1996.

[31] McClay IS, Manal K. Coupling parameters in runners with normal and excessive pronation. Journal of Applied Biomechanics 1997;13:109-24.

[32] Levens AS, Inman VT, Blosser JA. Transverse rotation of the segments of the lower extremity in locomotion. Journal of Bone and Joint Surgery [Am] 1948;30:859-72.

[33] Lafortune MA, Cavanagh PR, Sommer III HJ, Kalenak A. Foot inversion-eversion and knee kinematics during walking. Journal of Orthopaedic Research 1994;12:412-20.

[34] Perry SD, Lafortune MA. Influences of inversion/eversion of the foot upon impact loading during locomotion. Clinical Biomechanics 1995;5:253-7.
[35] Smart G, Robertson G. Triplanar electrogoniometer analysis of running gait. In: Winter DA, et al. editors. Proceedings of the IXth International Congress of Biomechanics. Champaign: Human Kinetics, 1985:144-48.

[36] van Gheluwe W, Tielemans R, Roosen P. The influence of heel counter rigidity on rearfoot motion during running. Journal of Applied Biomechanics 1995;11:47-67.

[37] Stähelin T, Nigg BM, van den Bogert AJ, Stefanyshyn DJ, Herzog W. Die Rolle dynamischer Stabilisatoren bei der Kontrolle von Knochenbewegungen des Sprunggelenkkomplexes. [The role of dynamic stabilisers controlling the movement of bones at the ankle]. Schweizerische Medizinische Wochenschrift 1997;127 Suppl. 91:35S.

[38] Fromme A, Winkelmann F, Thorwesten L, Reer R, Jerosch J. Dependency of rearfoot pronation on physical strain during running. Sportverletzungen, Sportschaden 1997;11:52-7.

[39] Engsberg JR, Andrews JG. Kinematic analysis of the talocalcaneal/talocrural joint during running support. Medicine and Science in Sports and Exercise 1987;19(3):275-84. 